\title{
ASSESSMENT OF THE DEPTH OF CURE OF RESIN COMPOSITE RESTORATION BY USING TRANS-TOOTH CURING TECHNIQUE WITH DIFFERENT LIGHT CURING INTENSITIES
}

\author{
Rasha Raafat*
}

\begin{abstract}
Statement of problem: failure of resin composite restoration is most frequently caused by improper polymerization; it would be advantageous if the restoration possessed optimal depth of cure. Objective: The purpose of this study was to the depth of cure of resin composite restoration by using Trans-tooth curing technique with different light curing intensities

Material and methods: A total of 20 sound, non-carious human maxillary anterior teeth, were used in this study. The teeth were divided into 2 main groups of 10 teeth each according to the thickness of the labial tooth structure plate (T); either $1.5 \mathrm{~mm}$ plate thickness (T1) or $1 \mathrm{~mm}$ plate thickness (T2). Each main group was subdivided into 2 subgroups of 5 teeth each according to the intensity of the light curing (I); either conventional intensity light curing $\left(\mathrm{I}_{1}\right)$, or high intensity light curing $\left(\mathrm{I}_{2}\right)$. Two Standardized class III cavity preparations were prepared in the proximals and lingual surfaces. Resin composite restorations were applied then all the teeth prepared for micro-hardness assessment. Data were explored for normality using Kolmogorov-Smirnov test of normality. The results of Kolmogorov-Smirnov test indicated that most of data were normally distributed (parametric data), therefore, one-way analysis of variance (ANOVA) test was used to compare between groups. This was followed by Tukey's post hoc test and independent $t$ test for pairwise comparisons. The significance level was set at $\mathrm{p}<0.05$.
\end{abstract}

Results: Comparing all groups revealed that the highest mean value was recorded in High intensity curing $(1.5 \mathrm{~mm})$, whereas the lowest mean value was recorded in conventional intensity curing at $1.5 \mathrm{~mm}$. ANOVA test revealed that the difference between all groups was statistically significant $(\mathrm{P}=0.001)$.

Conclusions: Under the limitation of this in-vitro study it can be concluded that the thickness of the tooth structure as trans-tooth curing technique was applied is greatly affect the amount of light energy reached to the resin composite restoration. So therefore subsequently affect the degree of conversion of the composite restoration rather than the degree of light intensity.

* Lecturer of Conservative Dentistry, Faculty of Dentistry, Cairo University, Egypt. 


\section{INTRODUCTION}

Light-cured resin composites restoration have become increasingly popular as their introduction in the 1970s, allowing dental restorations to be more conservative and aesthetic. The degree of cure of composite is affected by many factors as intensity of the curing units, the exposure time, the resin shade, the filler size, and the filer loading level ${ }^{(8)}$. Power density levels are fundamental for providing an adequate depth of cure for resin composite restorations. Improper cure of the restoration leads to degradations of physical and biological properties of the resin composite ${ }^{(6)}$. In order to obtain optimal physical properties and clinical performance in resin composite restorations, it is necessary for a dental resin composite to have the greatest quantity of its monomer converted to polymer during the polymerization reaction ${ }^{19}$. Effective polymerization of the adhesive bond system and resin composite is required to obtain long-term clinical performance (2). However, there are many variables that affect the amount of light energy received at the top and bottom surfaces of a resin composite restoration, resulting in ineffective polymerization, as distance of the light guide tip from the resin composite, power density of curing unit, exposure duration, shade and opacity of the resin composite and increment thickness ${ }^{(13)}$.

Light transmission through dentin and enamel is not well known. It has not been reported in the literature whether the thickness of hard tissues of the tooth would affect the depth of cure of resin composite restorations when the light of curing unite passes through them ${ }^{(15)}$ If the restoration does not receive sufficient energy, various problems may arise, e.g., reduced degree of conversion, increased cytotoxicity, reduced hardness, increased pigmentation, increased wear, increased marginal breakdown and weak bond among the tooth, adhesive and the restoration ${ }^{(16)}$. Also If the less polymerized resin composite comes into contact with the pulp tissue, the remaining monomer can result in post restorative sensitivity, because of its toxicity. As these monomers can easily diffuse inward beyond the dentin and cause an inflammatory reaction in the pulp ${ }^{(17)}$. The degree of conversion of resin composites can be assessed by various methods. Direct techniques such as FTIR or Raman spectroscopy ${ }^{(3)}$.

However, these techniques are time consuming and complex. Micro-hardness measurements are widely used to evaluate resin composite cure and provide good estimation of the degree of conversion of resin composites ${ }^{(11)}$.

Two hypotheses were tested in this study:

(1) an increase in the light curing intensity would increase the depth of cure;

(2) an increase in thickness of hard tooth structure through which the light pass would not affect the degree of polymerization of resin composite.

\section{MATERIALS AND METHODS}

\section{Selection of teeth:}

A total of 20 sound, non-carious human maxillary anterior teeth, were used in this study. All selected teeth were free of caries, cracks and with no apparent hypoplastic defects. The selected teeth were thoroughly cleaned from calculus, tissue deposits, polished with pumice and polishing brush (Prophy Brush, yilong, china )at low speed. The teeth were stored in distilled water until use.

\section{Grouping of teeth:}

The teeth were divided into 2 main groups of 10 teeth each according to the thickness of the labial tooth structure plate (T); either $1.5 \mathrm{~mm}$ plate thickness $\left(\mathbf{T}_{1}\right)$ or $1 \mathrm{~mm}$ plate thickness $\left(\mathbf{T}_{2}\right)$. Each main group was subdivided into 2 subgroups of 5 teeth each according to the intensity of the light curing (I); either conventional intensity light curing $\left(\mathbf{I}_{1}\right)$, or high intensity light curing $\left(\mathbf{I}_{2}\right)$. 


\section{Preparation of cavities:}

First, a line was drawn at cemento-enamel junction to ensure that all preparations are in enamel. 2 lines was drawn representing the middle third of the proximal and lingual surfaces of each anterior tooth for standardization of the position of the cavity as the cavity was prepared centralized in-between the 2 lines. Two Standardized class III cavity preparations were prepared in the proximals and lingual surfaces using no. 245 carbide bur (Healthico, USA) in a high speed hand-piece (PANA MAX, NSK, Japan) under copious amount of water. Then the thickness of labial plate was checked axially with a precise caliper. As half of teeth with $1.5 \mathrm{~mm}$ labial plate thickness and the other half with $1 \mathrm{~mm}$ thickness.

\section{Application of adhesive and resin composite:}

Selective etching for enamel margin is performed using 35\% orthophosphoric acid etching gel for 30 seconds Then etching gel was removed by high suction, and the cavity was rinsed for 20 seconds. Adhesive system single bond universal system (3M ESPE) was applied with agitation for 10 seconds and followed by air thinning for 5 seconds then cured with LED curing unite (Dr's light AT, Good doctors co.ltd. korea) for 20 seconds. All prepared cavities were restored by packing nano-filled resin composite (Filtex Z350XT, 3M, ESPE) shade A3 using a gold-plated composite applicator (Miltax, Germany). Resin composites were light cured from the labial surface (trans-tooth curing technique) with LED curing unit (Dr's light AT, Good doctors co.ltd. korea) according to the group division using LED light curing unit using different light intensity with light curing tip at zero distance from the surface of resin composite. For $\mathrm{I}_{1}$ group, standard light curing intensity $(800 \mathrm{~mW} / \mathrm{cm} 2)$ was used for 40 seconds while for group $\mathrm{I}_{2}$ high intensity light curing mode $(1400 \mathrm{~mW} / \mathrm{cm} 2)$ was used for 20 seconds according to manufacturer instructions. the light intensity was checked every time with radiometer. Finishing \& polishing of composite surface was done using a finishing and polishing kit (No 1.020 Finishing and Polishing Kit, TOR VM, Russia). All teeth were stored in distilled water, for 24 hours before testing.

\section{Depth of cure assessment:}

Every tooth was flattened in a mesio-distal direction low speed diamond disc under copious water coolant, then the roots were cut below cemento-enamel junction by $2 \mathrm{~mm}$. Each tooth was poured in acrylic resin block horizontally leaving the cut surface uncovered. Finishing and polishing of the cut surface was performed before using the same finishing and polishing kit.

\section{Micro-hardness measurement:}

The Vickers hardness number (VHN) was determined on the top, middle and the bottom surfaces for each restoration using Digital Display Vickers Micro-hardness Tester (Model HVS50, Laizhou Huayin Testing Instrument Co., Ltd. China), with a Vickers diamond indenter and a 20X objective lens. A load of $200 \mathrm{~g}$ was applied to the surface of the specimens for 10 seconds. Microhardness was obtained using the following equation (10):HV=1.854 $\mathbf{P} / \mathbf{d}^{2}$ Where, $\mathbf{H V}$ is Vickers hardness in $\mathrm{Kgf} / \mathrm{mm}^{2}$, P is the load in $\mathrm{Kgf}$ and $\mathbf{d}$ is the length of the diagonals of indentation in mm. Vickers hardness percentage was calculated according to the following equation (11): $\mathrm{VH}=($ bottom $\mathrm{VHN}$ mean value / top VHN mean value) x $100 \%$.

\section{RESULTS}

Values were presented as mean and standard deviation (SD) values. Data were explored for normality using Kolmogorov-Smirnov test of normality. The results of Kolmogorov-Smirnov test indicated that most of data were normally distributed (parametric data), therefore, one-way analysis of variance (ANOVA) test was used to compare between groups. This was followed by Tukey's post hoc test and independent $t$ test for pairwise 
comparisons. The significance level was set at $\mathrm{p}<$ 0.05. Comparing all groups revealed that the highest mean value was recorded in High intensity curing $(1.5 \mathrm{~mm})$, whereas the lowest mean value was recorded in conventional intensity curing at $1.5 \mathrm{~mm}$. ANOVA test revealed that the difference between all groups was statistically significant $(\mathrm{P}=0.001)$.

TABLE (1) Comparison of all groups (ANOVA test)
Tukey's post hoc test revealed that conventional intensity curing at $1.5 \mathrm{~mm}$ was significantly lower than all other 3 groups. However, High intensity curing (1 and $1.5 \mathrm{~mm})$ and Conventional intensity curing $(1 \mathrm{~mm})$ were not significantly different. (Table 1,2) Fig. 1)

\begin{tabular}{|c|c|c|c|c|c|c|c|c|c|}
\hline & \multirow[b]{2}{*}{ Mean } & \multirow[b]{2}{*}{ Std. Dev } & \multirow[b]{2}{*}{$\begin{array}{l}\text { Std. } \\
\text { Error }\end{array}$} & \multicolumn{2}{|c|}{$\begin{array}{l}95 \% \text { Confidence } \\
\text { Interval for Mean }\end{array}$} & \multirow[b]{2}{*}{ Min } & \multirow[b]{2}{*}{$\operatorname{Max}$} & \multirow[t]{2}{*}{$\mathrm{F}$} & \multirow[t]{2}{*}{$\mathrm{P}$} \\
\hline & & & & $\begin{array}{l}\text { Lower } \\
\text { Bound }\end{array}$ & $\begin{array}{l}\text { Upper } \\
\text { Bound }\end{array}$ & & & & \\
\hline High intensity curing ( $1 \mathrm{~mm})$ & $92.64^{\mathrm{a}}$ & 4.682 & 2.561 & 86.74 & 98.55 & 76 & 100 & & \\
\hline High intensity curing $(1.5 \mathrm{~mm})$ & $96.12^{\mathrm{a}}$ & 2.974 & .991 & 93.84 & 98.41 & 90 & 100 & 7.208 & $0.001 *$ \\
\hline Conventional intensity curing ( $1 \mathrm{~mm})$ & $93.43^{\mathrm{a}}$ & 3.862 & 2.287 & 88.16 & 98.71 & 80 & 100 & & \\
\hline Conventional intensity curing $(1.5 \mathrm{~mm})$ & $88.38^{\mathrm{b}}$ & 2.247 & 2.082 & 83.58 & 93.18 & 78 & 96 & & \\
\hline
\end{tabular}

Significance level $p<0.05$, significant

TABLE (2) Pairwise Comparison between groups (independent $t$ test)

\begin{tabular}{|l|c|c|c|c|}
\hline & $\begin{array}{c}\text { High intensity } \\
\text { curing }(1 \mathrm{~mm})\end{array}$ & $\begin{array}{c}\text { High intensity } \\
\text { curing }(1.5 \mathrm{~mm})\end{array}$ & $\begin{array}{c}\text { Conventional intensity } \\
\text { curing }(1 \mathrm{~mm})\end{array}$ & $\begin{array}{c}\text { conventional intensity } \\
\text { curing at } 1.5 \mathrm{~mm}\end{array}$ \\
\hline High intensity curing $(1 \mathrm{~mm})$ & -------- & $0.0788 \mathrm{NS}$ & $0.7031 \mathrm{NS}$ & $0.026^{*}$ \\
\hline High intensity curing $(1.5 \mathrm{~mm})$ & $0.0788 \mathrm{NS}$ & ----- & $0.1192 \mathrm{NS}$ & $<0.0001^{*}$ \\
\hline Conventional intensity curing $(1 \mathrm{~mm})$ & $0.7031 \mathrm{NS}$ & $0.1192 \mathrm{NS}$ & --------- & $0.0039 *$ \\
\hline Conventional intensity curing at $1.5 \mathrm{~mm}$ & $0.026^{*}$ & $<0.0001^{*}$ & $0.0039^{*}$ & ------------ \\
\hline
\end{tabular}

Significance level $p<0.05, N S=$ non-significant, * significant

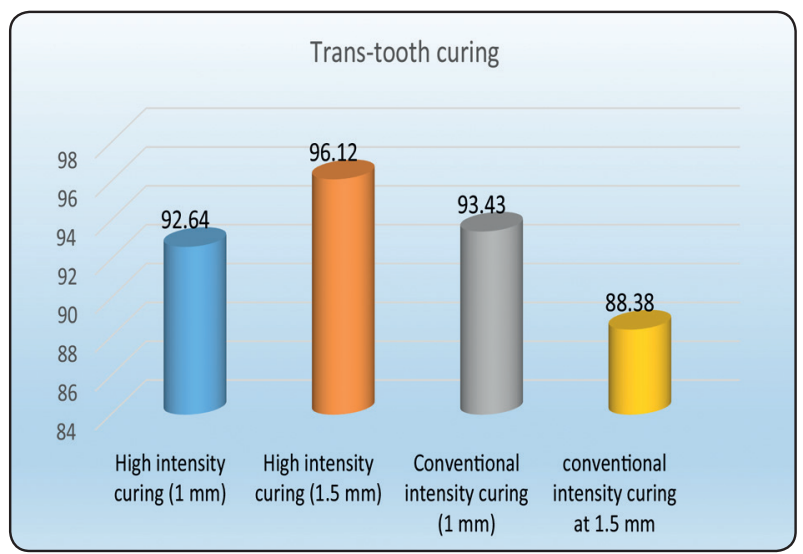

Fig. (1) Column chart showing mean value in all groups

\section{DISCUSSION}

Adequate polymerization is a crucial factor in gaining an optimal physical performance of resin compsite and for certain it is related to better clinical performance ${ }^{(2)}$. Light transmission through human tooth structures became an issue of interest when resin based light cured adhesives systems spread in widely use and due to increased use of indirectly luted restorations which are bonded with dual curing resin composite luting cements ${ }^{(8)}$. 
There are many variables that affect the amount of light energy received at the top and bottom surfaces of a resin composite restoration as curing Depth, Light Intensity and Polymerization Time. That determining whether or not a composite restoration is completely cured which is considered one of the largest challenges in the clinical practice. Usualy the uppermost layer is cured almost immediately while the deeper areas are still reacting ${ }^{(7)}$. Aguiar et al., 2005 ${ }^{(2)}$ stated that the hardness ratio between bottom and top surface should be " 1 " in order to consider the polymerization completely effective, but a ratio of up to "around 0.8 " could be considered as an adequate polymerization. light transmission is considerably influenced when there is dentin or enamel between the light source and a light irradiance power detector. This issue has relevance when light curing adhesives and resin composites are cured through dentin and enamel ${ }^{(15)}$.

Therefore, two different tooth structure plate thickness were prepared in class III cavities to assess the effect of thickness of enamel and dentin on the degree of curing of resin composite restoration with different two light intensities. In this current study trans-tooth curing technique of resin composite was adopted for its benefit in decreasing the polymerization shrinkage gape created at the interface between the tooth structure and restoration, as it is well-known a technique for guided polymerization. Resin composites restorations may cure to different degree due to the great variety in resin composites composition, curing units, light intensities and curing protocol ${ }^{(8)}$.

Hence, to assess the effectiveness of the curing of resin composite restoration to achieve proper depth of cure with different light intensities, type of composite was standardized by using a nanofilled resin composite (Filtex Z350XT, 3M, ESPE) shade A3. Also the light curing unite was unify but with different light intensities either conventional $\left(800 \mathrm{~mW} / \mathrm{cm}^{2}\right)$ or high intensity $\left(1400 \mathrm{~mW} / \mathrm{cm}^{2}\right)$ to ensure the standardization in this study. The degree of polymerization plays an important role in physical and mechanical properties of composite materials ${ }^{[13]}$. There are many direct and indirect methods for investigating the depth of cure. Infrared spectroscopy and laser raman are direct methods on other hand micro-hardness, scratching and visual inspection are some of the indirect methods (4). Direct methods are complicated, expensive and time consuming; while, micro-hardness testing is to be the most popular method for measuring and assess the depth of cure. Surface micro-hardness (Vickers or Knoop) has been shown to be an adequate indicator of the degree of conversion and correlates with the infrared spectroscopy ${ }^{(4)}$. The bottom to top hardness ratios ranging from 0.80 0.90 have been used as criteria for the adequate degree of conversion ${ }^{(9,12)}$. It means that the bottom to top surface micro-hardness ratio of $80 \%$ or more is considered adequate curing ${ }^{(2)}$. The results of this study showed statistically significant difference among all the tested group. As the high intensity $(1.5 \mathrm{~mm}, 1 \mathrm{~mm})$ and conventional intensity with $1 \mathrm{~mm}$ tooth plate thickness showed high percentages of degree of conversion but with no statistically significant difference between them. Harrington and Wilson ${ }^{(7)}$ reported that the light curing intensity at the resin composite surface decreased when the light tip was held at a distance from the composite instead of close contact between them. Thus, differences in power intensity did not result in differences in the degree of conversion of the optimally cured resin composite material, as determined by hardness measurements. This could explain my result that the high intensity light cure didn't show statistically significantly difference between the high intensity and the conventional one, especially with decreased tooth structure thickness $(1 \mathrm{~mm})$ with conventional light intensity. As, decreasing the amount of tooth structure passes by the curing light minimizing the mount of light scattering and light energy attenuation during the polymerization procedure. This result 
is in corroborates with the finding of Rueggeberg

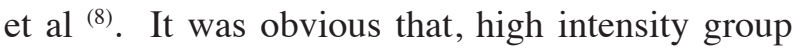
with $1 \mathrm{~mm}$ tooth structure thickness reported highest depth of cure as compared to the other group due to decreasing the distance between the light curing tip and resin composite restoration so reduce the amount of light scattering and energy attenuation when the light passes through enamel and dentin producing so could guarantee adequate depth of cure ${ }^{(15)}$. Also, this was in agreement with ${ }^{(17)}$ whom stated that, the resin composite has the property of dispersing the light of the light curing unit, so when the light passes through the bulk of the resin composite, light intensity is attenuated due to the light being scattered by filler particles and the resin matrix. Regarding the results of this current study we can found that the resin composite restoration that cured with conventional light intensity at 1.5 $\mathrm{mm}$ thickness of tooth structure was recorded the lowest percentage of the depth of cure among the other groups.

This is could be attributed to increasing the distance between the light curing tip and resin composite; $1.5 \mathrm{~mm}$ thickness, accompanied with low light intensity used. all these conjugated to result in decreasing the percentage of depth of cure of this group. As the energy is attenuated and dispersed with increasing material depth with a risk that al the monomer may not convert into a polymer. this was in the same track with the results of Meyer et $\mathrm{al}^{(10)}$ who observed that LED curing units showed a significant decrease in power density when the light tip-resin composite distance was increased than $0 \mathrm{~mm}$.

\section{CONCLUSIONS}

Under the limitation of this in-vitro study it can be concluded that the thickness of the tooth structure as trans-tooth curing technique was applied is greatly affect the amount of light energy reached to the resin composite restoration. So therefore subsequently affect the degree of conversion of the composite restoration rather than the degree of light intensity. This lead us to reject the both null hypotheses of this study.

\section{REFERENCES}

1. Abed Y.A., Sabry H.A., and Alrobeigy N.A. (2015). 'Degree of conversion and surface hardness of bulk-fill composite versus incremental-fill composite'. Tanta Dental Journal, 12 (2):71-80.

2. Aguiar F., Lazzari C., Leite Lima D., Ambrosano G., Lovadino J., (2005)Effect of light curing tip distance and resin shade on microhardness of a hybrid resin composite. Braz Oral Res;19(4):302-6.

3. Caldas DBM., Almeida JB, Correr-Sobrinho L., Sinhoreti MAC., Consani S. (2003) Influence of curing tip distance on resin composite Knoop hardness number, using three different light curing units. Oper Dent; 28:315-20.

4. Correr Sobrinho L., Lima AA., Consani S., Sinhoreti MAC., Knowles JC. (2000) Influence of curing tip distance on composite Knoop hardness values. Braz Dent J; $11: 11-7$.

5. Dash, S. and Kallepalli, S., (2015). 'An evaluation of the effect of Alcohol and Non-Alcohol based mouth rinses on the micro-hardness of two esthetic restorative materialsAn in vitro Study'. International Journal of Applied Dental Sciences, 1 (2):27-31.

6. Davidson CL, Feilzer AJ (1997) Polymerization shrinkage and polymerization shrinkage stress in polymer-based restoratives. J Dent 25:435-440.

7. Harrington E., Wilson HJ. (1993) Depth of cure of radiation activated materials - effect of mould material and cavity size. J Dent 21:305-311.

8. Lindberg A., Peutzfeldt A., van Dijken J., (2005) Effect of power density of curing unit, exposure duration, and light guide distance on composite depth of cure. Clin Oral Invest 9: 71-76.

9. Manhart J., Kunzelmann K-H., Chen HY., Hickel R. (2000) Mechanical properties and wear behavior of lightcured packable resin composites. Dent Mater; 16:33-40.

10. Meyer GR., Ernst C-P., Willershausen B. (2002) Decrease in power output of new light-emitting diode (LED) curing devices with increasing distance to filling surface. J Adhes Dent 4:197-204. 
11. Peutzfeldt A., Asmussen E. (2000) The effect of post curing on quantity of remaining double bonds, mechanical properties, and in vitro wear of two resin composites. J Dent 28:447-452.

12. Prati C., Chersoni S., Montebugnoli L., Montanari G. (1999) Effect of the air, dentin and resin-based composite thickness on light intensity reduction. Am J Dent; 12:231-4.

13. Price RB, Dérand T, Lonev RW, Andreou P. (2002) Effect of light source and specimen thickness on the surface hardness of resin composite. Am J Dent ;15:47-53.

14. Rueggeberg FA., Ergle JW., Mettenburg DJ. (2000) Polymerization depths of contemporary light-curing units using micro-hardness. J Esthet Dent 12:340-349.

15. Uusitalo E., Varrela J., Lassila L., Vallittu P.K., (2016) Transmission of Curing Light through Moist, Air-Dried, and EDTA Treated Dentine and Enamel BioMed Research International Article ID 5713962, 6 pages.

16. Yap AUJ., (2000) Effectiveness of polymerization in composite restoratives claiming bulk placement: impact of cavity depth and exposure time. Oper Dent; 25:113-20.

17. Yap AUJ, Wong NY, Siow KS ., (2003) Composite cure and shrinkage associated with high intensity curing light. Oper Dent; 28:357-64. 